\title{
APRS Data Receiver Using Raspberry Pi in LAPAN-A2 Satellite
}

\author{
Sofian Rizal $^{1}$, Sonny Dwi Harsono ${ }^{2}$, Suraduita Mupasanta ${ }^{3}$, Rifki Ardinal ${ }^{4}$ \\ ${ }^{1,2,3,4}$ Satellite Technology Center, Indonesian National Institute of Aeronautics and Space (LAPAN) \\ Jalan Cagak Satelit, Km. 04 Ranca Bungur, Bogor, West Java, Indonesia 16310
}

Email: sofian.rizal@lapan.go.id

\begin{abstract}
Lapan-A2 Satellite, also known as LAPAN-ORARI, is the second satellite developed by the Indonesian National Institute of Aeronautics and Space (LAPAN) especially by Satellite Technology Center. This satellite was launched in 2015 which one of the payloads is for amateur radio communication such as VR (Voice Repeater) and APRS (Automatic Packet Reporting System). The APRS is a method of transmitting messages, status and positions using certain range of frequency and often used by Search and Rescue (SAR) team. Due to its function, APRS are not only used for disaster mitigation but also transmit various kind of data such as text message and weather information. In order to receive such information, APRS must be equipped with supporting devices. Formerly, APRS utilize terminal node controller and special hardware to decode its information but those technology is quite expensive. To address that challenge, this paper proposed an alternative way to decode the information send both from satellite APRS and terrestrial APRS by using raspberry Pi to replace those high-cost system.
\end{abstract}

Keywords: APRS, Communication, LAPAN-A2, Raspberry Pi, Satellite

\section{Introduction}

The enhancement of today's communication technology is going more rapidly. A numerous variety of tools are used in communication such as utilization of radio waves to carry information. VR (Voice Repeater) and APRS (Automatic Packet Reporting System) is one of the examples for that type of communication. APRS is a radio packet application to transmit about position, short text messages and data telemetry. APRS is made by individual or group or institution and it is used for themselves but it does not rule out that other people can see the visualization of APRS data [1]. Additionally, the launch of various orbiting satellite carrying amateur radio payload (VR and APRS) also make a big impact in amateur radio development. The technology advancement also inspired amateur radio to develop its technical knowledge.
The missions of LAPAN-A2 Satellite are earth observation, ship monitoring by using Automatic Identification System (AIS), and amateur radio communication such as Voice Repeater (VR) and Automatic Package Reporting System (APRS) [2]. VR and APRS influence the groups of amateur radio operators especially in Indonesia (ORARI) to communicate throughout the world. APRS in LAPAN-2 Satellite also used for disaster mitigation in Indonesia. Through LAPAN-A2 Satellite ORARI members able to coordinate with SAR (Search and Rescue) team to find evacuation route and other things that could help the mitigation process [3].

Previously, APRS utilize terminal node controller and special hardware to decode the information but this technology is quite expensive. However, the use of those special hardware can be replaced by Mini PC 
such as Raspberry $\mathrm{Pi}$ to overcome cost issue. Its potential uses are staggering, and yet not fully explored, but it has already been tested as multimedia player with streaming capabilities, a games machine, an internet browser and a hardware development board. It is intended to be used as an educational device for people of all ages and skill levels [4]. Hopefully, with the benefit of Raspberry Pi can be considered as an alternative media in terms of low-cost and convenience side for receiving APRS data both from terrestrial APRS and Satellite APRS, especially to the amateur radio operators.

\section{Methodology}

The researcher's objective was to find out how to Receive data APRS from satellite and terrestrial using Raspberry Pi. The Information received is not only beacon text message from satellite but also weather data from terrestrial. This will be useful to radio operators because the beneficial of Raspberry $\mathrm{Pi}$ are easily learned and considerably low-cost system. Three main devices are needed in this objective, those are APRS and Ground Station system to show how to transmit APRS Data and Raspberry Pi with radio VHF to receive text messages from APRS both form satellite or terrestrial. The system design and workflow are also explained in this part.

\subsection{Main Devices}

\subsubsection{APRS and Ground Station}

One of the amateur radio's standard communications is using Automatic Packet Reporting System (APRS).
APRS is a digital communications system that use packet radio to send real time information on amateur radio frequencies. APRS used in terms of exchange big data in a widely area [5]. Information shared over the APRS network are station location, data telemetry, text message and weather data. Nowadays, APRS consist of widely wireless network and used by 40.000 users throughout the word. The internet gateway for APRS is known as an iGates. iGates collects packets from the radio and feeds them into a worldwide data stream on the internet [2].

LAPAN-A2 Satellite carry amateur radio payload including APRS. APRS is an amateur radio text message repeater that has been extensively used by amateur satellite community in Indonesia. Satellitebased amateur communication service via LAPAN-A2 was started in October 2015, one month after the launch of satellite and has served the amateur communication society in South America, India, and Southeast Asian countries [6]. Satellite Technology Center APRS ground station has a callsign YF1ZQA and LAPAN-A2 satellite, which has an APRS mission using callsign YBOX-1. LAPAN-A2 Satellite also used as digital repeater to retransmit data for extending coverages. The APRS digipeater of LAPAN-A2 Satellite is on $145.825 \mathrm{MHz}$ [2]. Thus, reliable ground station is needed to be able to communicate with satellite for collecting and transmitting the APRS data and Satellite Technology Center APRS Ground Station is able to do both .

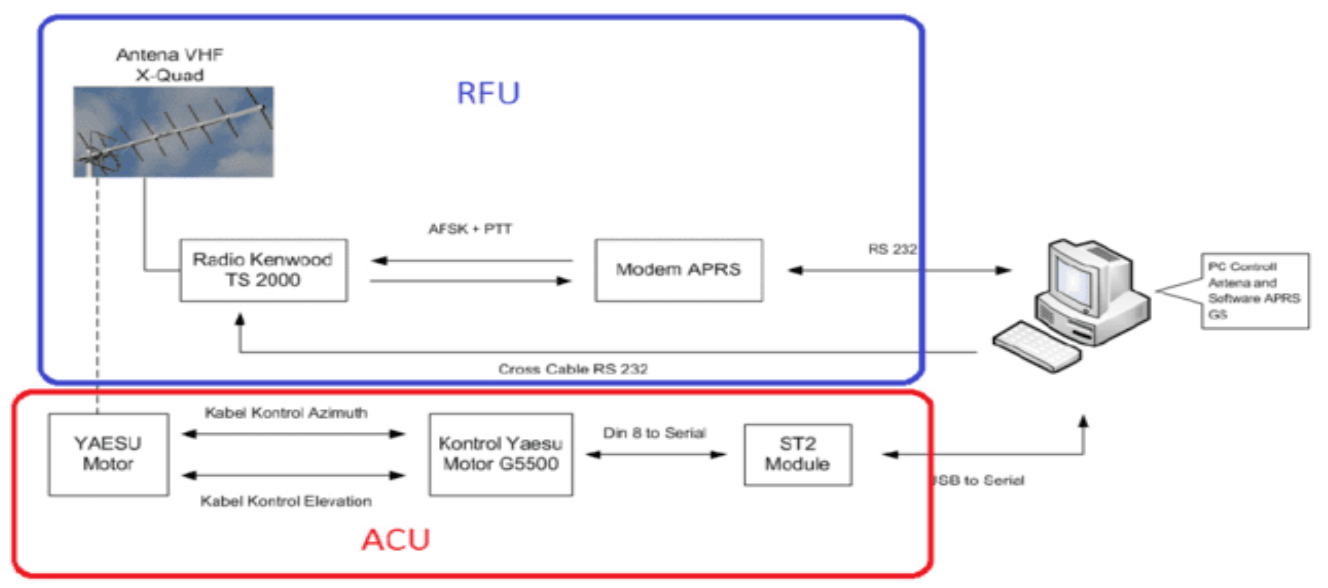

Figure 1. Scheme of APRS Ground Station in Satellite Technology Center, Bogor [3] 
The Configuration of APRS ground station in Satellite Technology Center Bogor is divided by 2 units, Radio Frequency Unit (RFU) and Antenna Control Unit (ACU). RFU consist of VHF Yagi antenna, radio transceiver and APRS modem. Meanwhile ACU consist of Rotator, motor controller and PC [3].

APRS Ground station in Satellite Technology Center used cross Yagi Antenna due to the changing of antenna polarization from satellite. The changing of antenna polarization caused by the satellite movement. Therefore, Ground station should be able to receive signal which has horizontal and vertical polarization. The signal that would be transmitted is going through Radio Kenwood TS2000. APRS Modem (OT2) or widely known as terminal node controller (TNC) is used for terminal radio packet. The TNC is a device commonly used by amateur radio users using the AX.25 protocol. Besides receiving and transmitting APRS data packet, APRS modem is able to repeat the message and send to predefined path [3]. That function is also called digipeater. The radio signal will be demodulated by TNC, so it can be passed straight to a computer and then interpreted by special software.

Antenna Control Unit consist of Yaesu Motor, Yaesu Motor Controller and ST2 Module. Yaesu G-5500 used as controller due to its ability to control up to $450^{\circ}$ of azimuth and $180^{\circ}$ of elevation. ARS in APRS Ground Station is using ST2 Module. ST2 Module is an interface to control the antenna using PC [3].

Reliable configuration above is needed to smooth the transmit data process from ground station to satellite. The data that will be transmitted can be weather data or text messages. LAPAN-A2 will repeat those data to be accepted all over the satellite's coverage.

\subsubsection{Raspberry Pi}

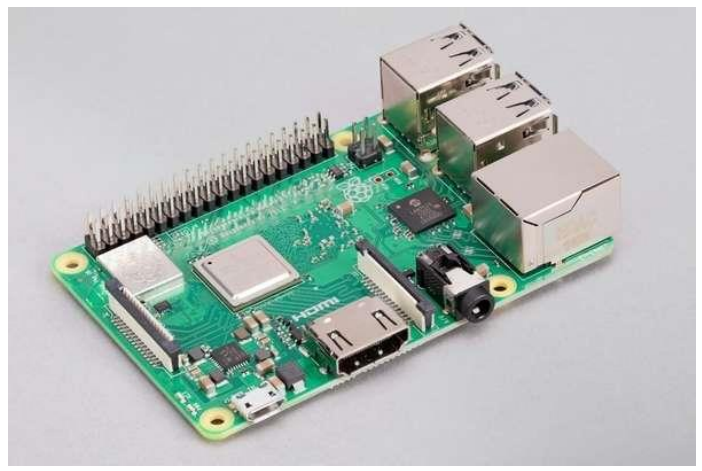

Figure 2. APRS Raspberry Pi 3 B+ [7]
Raspberry $\mathrm{Pi}$ is a tiny and affordable computer. Developed by Raspberry Pi foundation in United Kingdom, this device consists of SoC (System on Chip), RAM (Random Acces Memory), Radio Module, PMIC (Power Management Integrated Circuit), USB Port, Ethernet Port, Micro SD Card, GPIO Header, Display Connector, Power Input, HDMI, Camera Connector + AV Jack.

Various models of Raspberry Pi have been released since the original model $\mathrm{B}$, each bringing either improved specifications or features specific to a particular use-case [10]. In this study, Raspberry Pi 3 $\mathrm{B}+$ is used. The Raspberry Pi 3 Model $\mathrm{B}+$ is the latest product in the raspberry $\mathrm{Pi} 3$ range, boasting a 64-bit quad core processor running at 1.4GHZ, dual-band 2.4 $\mathrm{GHz}$ and $5 \mathrm{GHz}$ wireless LAN, Bluetooth 4.2/BLE, faster ethernet, and PoE capability via a separate PoE HAT.

The dual-band wireless LAN comes with modular compliance certification, allowing the board to be designed into end products with significantly reduced wireless LAN compliance testing, improving both cost and time to market.

The Raspberry Pi 3 Model B+ maintains the same mechanical footprint as both the Raspberry Pi 2 Model B and the Raspberry Pi 3 Model B [7]. The detail specifications are as follows.

Table 1. APRS Raspberry Pi 3 B+ Specifications

\begin{tabular}{cl}
\hline Specifications & \multicolumn{1}{c}{ Detail } \\
\hline Processor & Broadcom \\
& BCM2873B0, \\
& Cortex-A53 64-Bit \\
& SoC @ 1.4 GHZ \\
\hline Memory & 1GB LPDDR2 \\
& SDRAM \\
\hline Connectivity & 2,4 GHz and 5 GHz \\
& IEEE 802. 11.b/g/n \\
& wireless LAN, \\
& Bluetooth 4.2, BLE. \\
& Gigabit Ethernet over \\
& USB 2.0 (maximum \\
& throughput 300 \\
& Mbps). 4 x USB 2.0 \\
& Ports \\
\hline Access & Extended 40-pin \\
& GPIO header \\
\hline
\end{tabular}




\begin{tabular}{|c|c|}
\hline $\begin{array}{l}\text { Video } \\
\text { Sound }\end{array}$ & $\begin{array}{l}1 \quad \mathrm{x} \text { full size } \\
\text { HDMI. MIPI DSI } \\
\text { display port. } 2 \text { MIPI } \\
\text { CSI camera port. } \\
4 \text { pole stereo output } \\
\text { and composite video } \\
\text { port }\end{array}$ \\
\hline Multimedia & $\begin{array}{l}\text { H.264, MPEG-4 } \\
\text { decode (1080p30); } \\
\text { H.264 encode } \\
(1080 \text { p30); OpenGL } \\
\text { ES } 1.1,2.0\end{array}$ \\
\hline $\begin{array}{c}\text { SD } \\
\text { support }\end{array}$ & $\begin{array}{l}\text { Micro SD format for } \\
\text { loading operating } \\
\text { system and data } \\
\text { storage }\end{array}$ \\
\hline Input Power & $\begin{array}{l}\text { 5V/2.5 A DC via } \\
\text { micro USB } \\
\text { connector. 5V DC vua } \\
\text { GPIO header } \\
\text { Power over ethernet } \\
\text { (PoE) - enabled } \\
\text { (requires separate } \\
\text { PoE HAT) }\end{array}$ \\
\hline Environment & $\begin{array}{l}\text { Operating } \\
\text { temperature, } \quad 0-50 \\
\text { degree celcius }\end{array}$ \\
\hline
\end{tabular}

The Raspberry Pi Model B is more expensive than the previous model, but comes with considerable advantages. For many users Model B is a worthwile investment. The Model B has two USB on the righthand edge of the board, providing more connectivity. Only those with particular requirements of weight, space or power draw should consider the previous model for general-purpose use [4].

\subsubsection{IC-V8 VHF Transceiver}

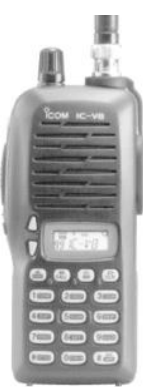

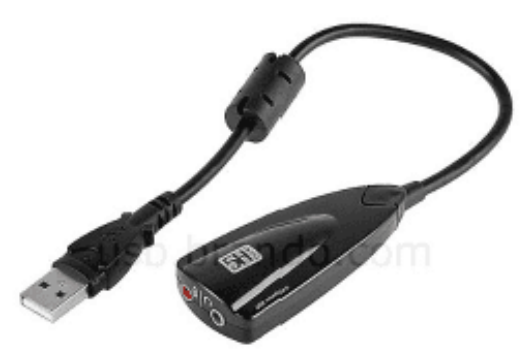

Figure 4. USB Soundcard [4]

IC-V8 is VHF radio used to receive frequency signal 145.825 form LAPAN A2 satellite. This signal will be converted and displayed in Raspberry Pi's LCD. This radio equipped by antenna and belt clip. The detail specification of IC-V8 Transceiver is as follows [6].

Table 2. Transceiver IC-V8 Specification

\begin{tabular}{|c|c|}
\hline Specifications & Detail \\
\hline $\begin{array}{ll}\begin{array}{l}\text { Frequency } \\
\text { (General) }\end{array} & \text { Range } \\
\end{array}$ & $\begin{array}{l}136-174 \mathrm{MHz}^{*} \\
(\mathrm{Tx} / \mathrm{Rx}) \\
\text { *Guaranteed } 144- \\
148 \mathrm{MHz} \text { range } \\
\text { Only }\end{array}$ \\
\hline Operating temp. Range & $-10^{\circ} \mathrm{C}$ to $+60^{\circ} \mathrm{C}$ \\
\hline Antenna Connector & $\mathrm{BNC}(50 \Omega)$ \\
\hline $\begin{array}{ll}\text { Power } & \text { Supply } \\
\text { Requirement } & \end{array}$ & $\begin{array}{l}\text { 7.2V DC (6-10.3 } \\
\text { V DC acceptable; } \\
\text { Icom's battery } \\
\text { pack only) }\end{array}$ \\
\hline 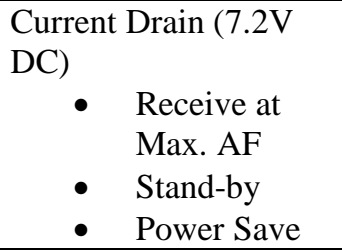 & $\begin{array}{l}\text { Less Than } 250 \\
\mathrm{~mA} \\
\text { Less Than } 70 \mathrm{~mA} \\
\text { Less Than } 20 \mathrm{~mA}\end{array}$ \\
\hline Tuning Steps & $\begin{array}{l}5,10,12.5,15,20,3 \\
5 \text { and } 50 \mathrm{kHz}\end{array}$ \\
\hline Dimensions & $\begin{array}{l}54(\mathrm{~W}) \times 132 \\
(\mathrm{H}) \times 35(\mathrm{D}) \mathrm{mm}\end{array}$ \\
\hline Weight & $\begin{array}{l}350 \mathrm{~g} \text { (with BP- } \\
222 \text { ) } \\
190 \mathrm{~g} \text { (without } \\
\text { batter pack) }\end{array}$ \\
\hline
\end{tabular}

\subsubsection{USB Soundcard}

Figure 3. Transceiver IC-V8 
A soundcard also known as an audio card is an internal computer expansion card that facilitates economical input and output of audio signals to and frorm a computer under control of computer programs [4]. Soundcard play an important role especially for APRS receiver process. By using computer's sound card, audio from the radio can be processed using software, which will decode received packets, or audio can be played from the soundcard to the radio to be transmitted [11].

USB soundcard, sometimes called audio interfaces, are usually external boxes that plug into computer USB such as figure 4. Audio interfaces may describe a device allowing a computer which has a sound-card, yet lack a standard audio socket, to be connected to an external device which requires such a socker, via its USB socket [4]

\subsection{System Configuration}

In this objective, the Raspberry Pi system receive data both from satellite and from terrestrial. To be able to receive such information other supported devices are needed. The workflow and the block diagram of both configurations are explained as follows.

\subsubsection{APRS Data from Satellite}

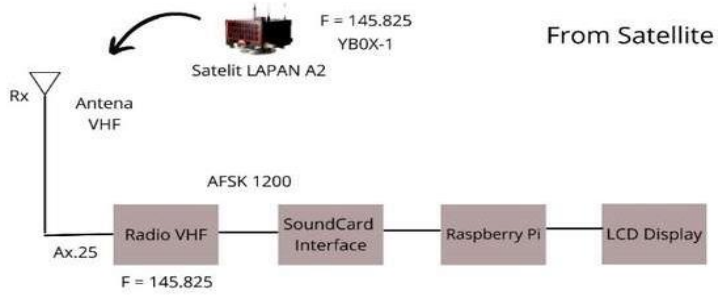

Figure 5. Block Diagram of Data Receiver from Satellite using Raspberry Pi

Figure 5 shows block diagram of data receiver from satellite using raspberry $\mathrm{Pi}$. Before explaining the receiver system, firstly transmit system to satellite will be discussed.

Ground station will transmit data to satellite, when LAPAN-A2 Satellite is in its coverage, the Ground station will transmit data to satellite and the satellite will repeat the data in order to spread the data in a wider scope of area. It's called digipeater or digital repeater, so the distance of data received by ground station is wider than digipeater from terrestrial. However, APRS payload in LAPAN-A2 Satellite, called YB0X-1, only active in determined time based on schedule. The schedule shown in figure 6 . the APRS data will be transmit in predetermined frequency $145.825 \mathrm{MHz}$.

In the receiver system, as shows in figure 5, the data that repeated by satellite is received by VHF Antenna that connected to VHF Radio IC-V8 using AX.25 protocol. The radio VHF should be setting to 145.825 $\mathrm{MHz}$ so it's able to receive data from satellite. The Audio Frequency-Shift Keying (AFSK) 1200 play an important role to decode the data from radio VHF so it can read by sound card interface. By using a soundcard interface, audio from the VHF radio can be processed by using the Raspberry Pi's software and use LCD to display the data that already been receive.

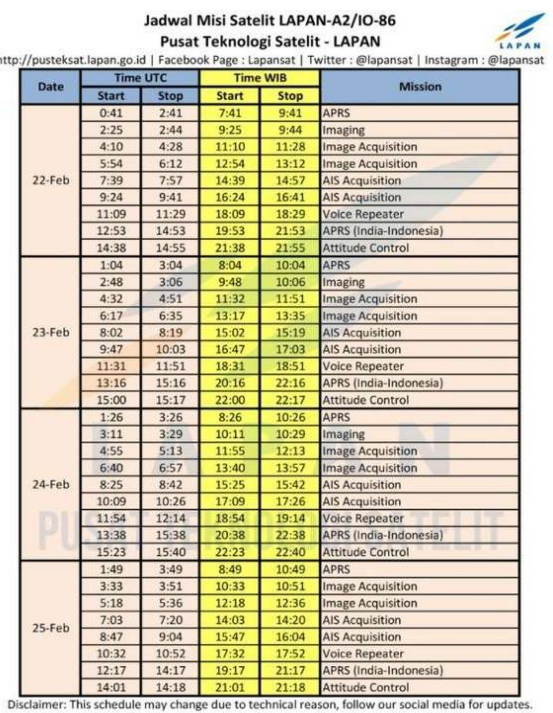

Figure 6. LAPAN-A2/IO-86 Mission Schedule, February 2021

Figure 6 shows LAPAN-A2 Satellite mission schedule on February 2021. APRS is activated twice a day in the morning around 07.00 to $09.00 \mathrm{WIB}$ and at night around 19.00-21.00 WIB. APRS is on when satellite passing through Indonesia and will be off in the second pass. Thus, it can be used as digipeater especially for country in equatorial area.

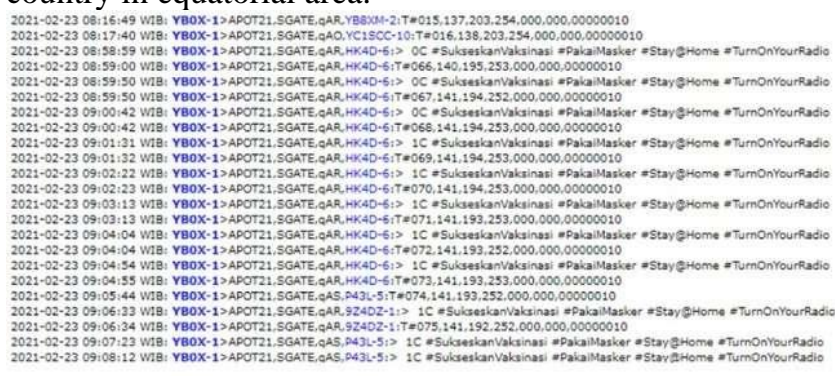

Figure 7. Beacon send by YB0X-1 in February [9] 
Figure 7 display information of text messages send by LAPAN-A2 Satellite, callsign YB0X-1, at 23 February 2021 taken from aprs.fi website. The aprs.fi web service collects information from the Automatic Packet (or position) Reporting System and used by amateur radio operators to transmit real-time position information, weather data, telemetry messages over the radio. Systems connected to the internet van send information without radio transmitter, or collect and display information transmitted anywhere in the world [9]

\subsubsection{APRS Data from Terrestrial}

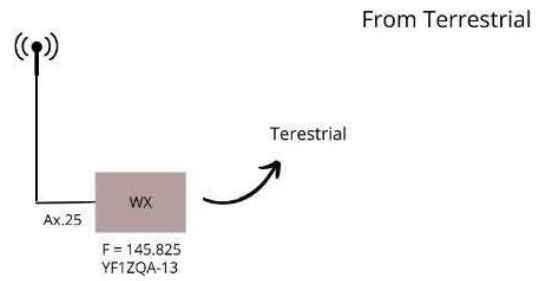

Figure 8. Block Diagram of APRS Data from Terrestrial

Figure 8 shows the APRS Terrestrial system. WX is a symbol for weather station. Rancabungur Ground Station also has APRS terrestrial for transmitting weather data such as humidity, temperature, rain and air pressure information. APRS terrestrial use 145.825 $\mathrm{MHz}$ as its frequency and YF1ZQA-13 as its callsign. Not having so much difference from APRS Data from Satellite, the weather data that transmit would be received by VHF Radio Transceiver IC-V8. With the same process the weather data would be displayed on Raspberry Pi's LCD.

\section{Result And Discussion}

Figure 9 shows the configuration of data receiver. ICOM IC-V8 is a VHF radio that used predetermined APRS downlink frequency $145.825 \mathrm{MHz}$. VHF radio passed the data to the soundcard interface. Sound card interface change the analog signal or audio signal to the digital signal so that the Raspberry Pi can process the data

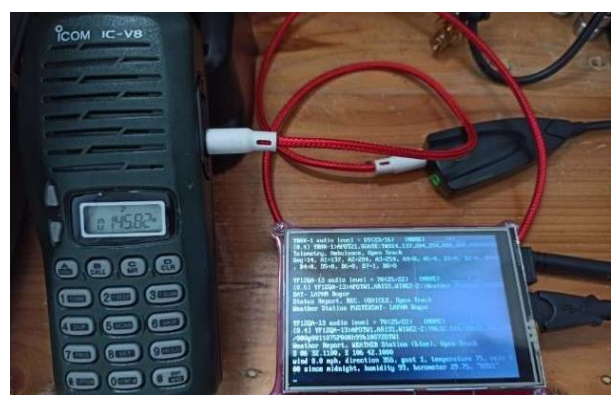

Figure 9. Configuration of data receiver using VHF Radio and Raspberry Pi

Figure 9 shows the display of beacon and weather station data from LAPAN-A2 satellite and APRS terrestrial in Rancabungur groundstation. As we can see, the basic configurations from weather station data are: callsign YF1ZQA-13; used path "ARISS, WIDE2-2"; weather information such as wind speed and direction, temperature, humidity and air pressure.

The text message from satellite also shown in the Raspberry Pi's display LCD. The basic configurations of the beacon text message are: callsign YB0X-1; used path "APOT21, SGATE" message text "\#SukseskanVaksinasi \#Stay@Home \#TurnOnyourRadio"

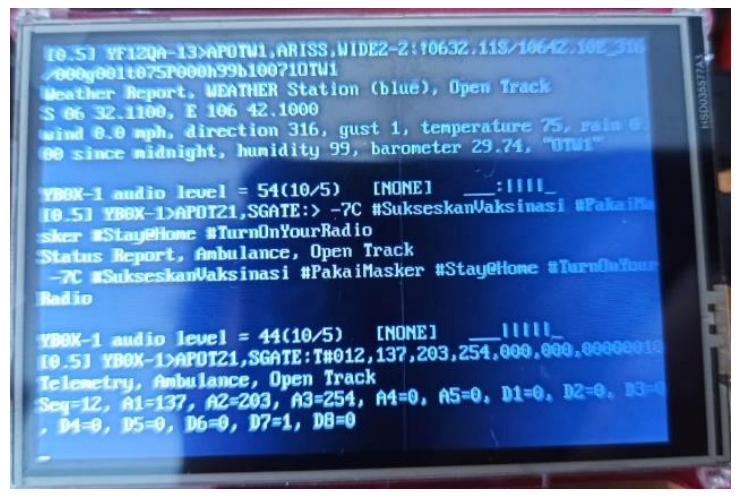

Figure 10. The display of beacon data and Weather Data from LAPAN-A2 Satellite

This system collected data from LAPAN-A2 satellite in operating frequency $145.825 \mathrm{MHz}$ and processed by Mini PC Raspberry Pi. By using this system, the APRS information from both satellite and terrestrial are successfully displayed in Raspberry $\mathrm{Pi}$ which also supported by VHF radio and soundcard interface. 


\section{Conclusion}

The simulation result show that the information both from satellite and terrestrial successfully displayed on the Raspberry Pi's LCD and can run well. Formerly, the receiver and transmitter APRS system use TNC modem and Computer and its rather expensive. During the enhancement of today's technology both hardware and software, the raspberry Pi become the answer to provide amateur radio operators excellent opportunities to overcome the difficulties in terms of highly operational cost.

\section{References}

[1] R. Hartono, I. Choiriyah, W. Hasbi, and R. Yatim. "Design Of APRS Modem Using IC TCM3105 and ATMEGA 2560 Microcontroller".International Journal Of Advanced Studies In Computer Science and Engineering IJASCSE Volume 7 Issue 2 (2018).

[2] S.D.Harsono, Rumadi and R.Ardinal "Design and Implementation of SatGate/iGate YF1ZQA for APRS on the LAPAN-A2 Satellite." IEEE International Conference on Aerospace Electronics and remote Sensing Technology (ICARES) (2019).
[3] R. Ardinal dan S. D. Harsono. "Sistem Stasiun Bumi Pemancar dan Penerima Data APRS pada Satelit LAPAN-A2." Prosiding SIPTEKGAN XXII, ISBN: 978-623-7102-02-01.

[4] S. D. Harsono. "Digital Communication Between Ground Station using raspberry Pi" International Seminar on Aerospace Science and Technology III.

[5] S.D. Harsono dan Z.R. Ardana. "Implementasi APRS Digital Repeater (Digipeater) Pada Stasiun Bumi." Seminar Nasional Iptek Penerbangan dan Antariksa XXIII (2019).

[6] R.H.Triharjanto, W.Hasbi and S.D. Harsono. Indonesia Non-GSO Satellites: Current Operations and Future Predictions. Buletin Pos dan Telekomunikasi Vol.17 No.1 (2019) 61-74

[7] Raspberry Pi 3 Model B+ Datasheet. Raspberry Pi Foundation.

[8] VHF Transceiver IC-V8 Instruction Manual. Icom Inc, 2002.

[9] aprs.fi (diakses 23 Februari 2021)

[10]G. Halfacree. "The Official Raspberry Pi Beginners Guide How To use Your New Computer".Raspberry Pi Press 2018

[11] R.F Campbell, Thesis, "Analysis of Various Algorithmic Approaches to Software Based 1200 Baud Audio Frequency Shift Keying Demodulaton for APRS", The Faculty of California Polytechnic State University, 2016. 